Revista Eletrônica do Programa de Pós-Graduação em Mídia e Cotidiano

Artigos Seção Livre

Número 4. Junho 2014

(C) 2014 by UFF

\title{
Boas histórias que o jornalismo quase deixou de contar: as redes sociais como pauta para a produção jornalística
}

\section{Good stories that journalism almost didn't tell: social networks as agenda for journalistic production}

\author{
Suzana ROZENDO ${ }^{1}$ \\ Criselli MONTIPÓ ${ }^{2}$
}

Resumo: O presente trabalho propõe-se a analisar a dinâmica das redes sociais Twitter e Facebook na coleta e na distribuição de notícias jornalísticas sobre pessoas em situação de rua. Para tanto, selecionou-se dois casos que demonstram o uso dessas plataformas para a formação de narrativas midiáticas sobre esse público: o de Daniel Morales, um dos participantes da Underheard, - iniciativa publicitária cujo propósito era permitir com que quatro sem-teto pudessem expressar seus pensamentos através do Twitter - e o de Raimundo Arruda Sobrinho, poeta que viveu durante vinte anos no canteiro central da Avenida Pedroso de Morais, na cidade de São Paulo, e teve um novo lar graças à criação de um perfil do Facebook. Como procedimentos metodológicos, utilizou-se o Estudo de Caso atrelado a uma análise crítica de mídia, com referencial teórico extraído de Jorge Pedro de Sousa (2002), Silvio Waisbord (2009), Patrick Champagne (1997), Theresa Frazão (2010), Sylvia Moretzsohn (2013) e Luiz Gonzaga Motta (2012).

Palavras-chave: Jornalismo, redes sociais, população em situação de rua, interesse público.

\begin{abstract}
${ }^{1}$ Mestre em Jornalismo pela Universidade Federal de Santa Catarina (2012) e doutoranda do PPGCOM/ECA/USP. E-mail: suzanarozendo@usp.br.

${ }^{2}$ Mestre em Jornalismo pela Universidade Federal de Santa Catarina (2012), pós-graduanda em Jornalismo Literário (ABJL). E-mail: criselli@ gmail.com. Telefone: (41) 3557-0167. Endereço Postal: Pontifícia Universidade Católica do Paraná - PUCPR. Rua Imaculada Conceição, 1155, Bairro Prado Velho, Curitiba, Paraná. CEP: 80215-901
\end{abstract}


This paper proposes to examine the dynamics of social networks Twitter and Facebook in the collection and distribution of news about homelesses. To this, it was selected two cases that demonstrate the use of these platforms to form media narratives about this public: Daniel Morales, one of the participants of Underheard - advertising initiative whose purpose was to allow four homelesses could express their thoughts through Twitter - and Raimundo Arruda Sobrinho, a poet who lived for twenty years in the Pedroso de Morais Avenue, in São Paulo, and had a new home thanks to the creation of a Facebook profile. The methodological procedures used were the Case Study coupled to a critical analysis of media, with the theoretical framework extracted of Jorge Pedro Sousa (2002), Silvio Waisbord (2009), Patrick Champagne (1997), Theresa Frazão (2010), Sylvia Moretzsohn (2013) and Luiz Gonzaga Motta (2012).

Keywords: Journalism, social networks, homeless, public interest.

\section{Apresentação}

Partindo da concepção de ciberacontecimento ${ }^{3}$ de Henn (2013), fatos repercutidos nas redes sociais geram intensa conversação e resultam em pautas jornalísticas nas mídias tradicionais, o presente trabalho parte da análise do Twitter e do Facebook na coleta e na distribuição de notícias sobre pessoas em situação de rua ${ }^{4}$. Neste sentido, foram selecionados dois casos (um estadunidense e outro brasileiro) que demonstram o uso das redes sociais para a formação de narrativas jornalísticas sobre esses cidadãos.

O primeiro refere-se a Daniel Morales, um dos participantes da Underheard, iniciativa publicitária cujo propósito era permitir com que quatro sem-teto pudessem expressar seus pensamentos através do Twitter. Após postar no microblog uma mensagem dizendo que estava à procura de sua filha Sarah Rivera, o tweet se espalhou

\footnotetext{
${ }^{3}$ Conforme Jungblut (2011), esse termo - "ciberacontecimento" - foi cunhado por Rafael Diaz Arias e, portanto, dá conta de episódios em que há propagação explosiva de informação no ciberespaço causada pela divulgação de fatos com grande capacidade de mobilização de atenção através de materiais visuais, sonoros ou audiovisuais.

${ }^{4}$ Os termos 'pessoa em situação de rua' e 'população de rua' vêm sendo adotados pela ciência e pelo Estado em seus discursos, trabalhos e leis, em detrimento de termos como 'mendigos' e 'sem teto'. São os termos mais aceitos na academia atualmente, portanto, iremos utilizá-los neste trabalho.
} 


\section{míDiA \\ $\mathrm{eP}$ DiAno}

pelos seus três mil seguidores e, no dia seguinte, pai e filha, que não se viam há uma década, retomaram o contato.

O segundo caso é o de Raimundo Arruda Sobrinho, poeta que viveu durante vinte anos no canteiro central da Avenida Pedroso de Morais, na cidade de São Paulo. Shalla Minteiro, uma de suas leitoras e apreciadoras de suas obras literárias criou um perfil no Facebook, em agosto de 2011, para divulgar os poemas do escritor. Menos de um mês depois, um dos irmãos de Raimundo, deparou-se com o perfil na rede social e, imediatamente, entrou em contato com Shalla, que mediou o encontro entre irmãos. Raimundo mudou-se para Goiânia e voltou a viver com a família.

Acontecimentos como os aqui relatados passaram a chamar a atenção da mídia convencional (jornais, sites noticiosos), que se interessou em noticiar os fatos insurgentes nas redes sociais. É importante destacar que, devido à dinamicidade das redes sociais, elas podem servir para controlar ou mesmo para ampliar a divulgação de temas esquecidos pela mídia.

O objetivo principal do trabalho é analisar a dinâmica das redes sociais e seus usuários na relação entre população de rua e a mídia jornalística. Como objetivo secundário, pretende-se discutir a apropriação das informações dos cibermeios pelo jornalismo convencional, partindo das experiências que envolvem população de rua.

Como procedimento metodológico utilizou-se o Estudo de Caso. Conforme Yin (2001), o Estudo de Caso é o método de pesquisa mais adequado quando se busca compreender fenômenos sociais complexos. De acordo com o referido autor, tal metodologia é a mais recomendada quando "o foco se encontra em fenômenos contemporâneos inseridos em algum contexto da vida real" (YIN, 2001, p.19). Yin destaca, também, que é um procedimento bastante usado para a análise de trabalhos da área jornalística.

Enfim, a análise da mídia nos ajuda a entender um pouco mais sobre quem produz e quem recebe a notícia e também a estabelecer alguns parâmetros culturais implícitos e a lógica organizacional oculta nas mensagens. 


\section{míDiA ecd DiAno}

\section{Redes sociais e jornalismo: uma pauta possível}

O jornalismo no mundo contemporâneo tem como grande função mediar a realidade social. Deste modo, pressupõe-se que os fatos que permeiam a complexidade cotidiana se transformem em narrativas jornalísticas. Morin (2006) destaca que o pensamento simplificador é incapaz de conceber a conjugação do uno e do múltiplo. "A incapacidade de conceber a complexidade da realidade antropossocial, em sua microdimensão (o ser individual) e em sua macrodimensão (o conjunto da humanidade planetária), conduz a infinitas tragédias e nos conduz à tragédia suprema" (MORIN, 2006, p. 13).

Tal visão se reflete nas redações e nega o contexto e a pluralidade. Prioriza as partes em vez de conceber o todo oportunizando um olhar mais sistêmico sobre os fenômenos. A pretensa obrigação jornalística de mostrar a realidade acaba por evidenciar apenas fragmentos das realidades, ora carregados de pré-julgamentos.

Os veículos jornalísticos da atualidade priorizam os fatos que envolvem figuras públicas ou pessoas famosas. Grande espaço é dado ao modelo hard news, notícias quentes ou factuais, e são cada vez mais raros os relatos que dão conta das boas histórias de anônimos a se contar.

Para Rincón (2006), um dos grandes desafios do jornalista contemporâneo é encontrar a narrativa da existência, falar sobre a vida cotidiana e contar sobre gente comum, detalhes e experiências universais que fazem parte do mundo e da vida. Para tanto se faz necessário um novo perfil de jornalista, um narrador que possa expressar sua autoria como sujeito vivente do mundo. Segundo o autor em pauta:

Narrar a informação é difícil. Fazê-la fora dos cânones da máquina convencional jornalística é muito difícil. Difícil, mas não impossível, porque criar um novo narrador jornalista implica aventurar novas visões, convencerse de que a narração pertence ao jornalista, que deve fazer dela sua fonte de registro e imaginação (RINCÓN, 2006, p. 127, tradução nossa). 


\section{PPGMC}

As narrativas - e em especial a jornalística - ajudam a compreender um pouco mais o ser humano na sua complexidade. Conforme Motta (2012), é a partir delas que entendemos o mundo humano, demarcamos nossas identidades e o que somos.

(...) As narrativas são uma prática humana universal, constituidoras de nossas experiências mais profundas e transcendentes, assim como nossas experiências mais felizes ou amargas: elas nos representam, são metáforas de nossas vidas, refletem nossa relação com o real e o irreal, estabelecem as fronteiras entre o bem o mal, o certo e o errado, instituem nossas sociedades, constituem nossas nações, nosso mundo (MOTTA, 2012, p. 32).

No entanto, é evidente a ausência de tais relatos em algumas instituições jornalísticas. O modo de produção acelerado, a diminuição de profissionais nas redações, a competitividade e a tendência em dar notícias da última hora colaboraram para a redução das pautas sobre histórias de vida, por exemplo. Paralelamente, outro caminho narrativo possível surgiu com o avanço tecnológico, que alterou as novas formas de obtenção, consumo e produção de informação. Nesse sentido, a Internet e as redes sociais passaram a ter um papel que, conforme Jorge Pedro de Sousa (2002), antes cabia apenas ao jornalismo: uma espécie de ágora. $\mathrm{Na}$ esfera online, o público pode compartilhar informações sem esbarrar em nenhum filtro empresarial, que muitas vezes é o responsável por desqualificar pautas que renderiam boas reportagens.

Em outras palavras, no atual cenário globalizado, as redes sociais vêm, cada vez mais, "dessacralizando" o domínio do campo jornalístico tradicional, à medida que as pessoas podem produzir conteúdo na Internet. Torna-se, portanto, um espaço bastante democrático onde os protagonistas (dos fatos e das narrativas) são pessoas comuns, inclusive aquelas em situação de rua.

Ao estudar o microblog Twitter, rede social em que um acontecimento pode ser experienciado de forma peculiar devido às características da ferramenta, Zago (2011) constatou que a utilização dessa rede para a circulação e recirculação de informação jornalística foi intensificada nos últimos cinco anos. De acordo com a pesquisadora, o Twitter permite a troca de informações de forma descentralizada entre interagentes 


\section{míDiA \\ ec DiAno}

situados em diversos pontos do ciberespaço e essa troca pode influenciar a mídia online de referência: "pode-se ficar sabendo pelo Twitter antes de ver nos jornais, a partir de um link, de uma crítica, e até mesmo a partir de uma piada" (ZAGO, 2011, p.165).

Seguindo a mesma linha de raciocínio, Ronaldo Henn (2013, p.8), a partir do caso da canadense Amanda Tood, uma adolescente que cometeu suicídio depois de postar um vídeo no Youtube em que relata intimidações sofridas no Facebook, comenta que "as redes sociais na internet são mais do que espaços de sociabilidade: são lugares profícuos para a eclosão de acontecimentos”.

Henn (2013, p. 13) explica que "o ciberacontecimento delineia-se num contexto de crise do jornalismo contemporâneo". Assim, no momento em que as redes sociais produzem uma enorme conversação pública - o que antes cabia restritamente à comunidade interpretativa dos jornalistas - novos arranjos comunitários também incorporam dinâmicas que são da ordem do jornalismo. Por serem criadas a partir das novas mídias, essas pautas são reenquadradas por múltiplos olhares e mediações sucessivas (RUBLESCK, 2011).

Certo é que para a imprensa funcionar eficazmente como uma plataforma para a manifestação dos interesses dos cidadãos, segundo Waisbord (2009), é preciso cultivar e manter vínculos fortes com a sociedade civil. "Esta é uma condição fundamental para que a imprensa possa alimentar a cidadania, cobrir perspectivas múltiplas, relatar as questões que afetam uma ampla diversidade de públicos e facilitar o diálogo civil e a participação dos cidadãos" (WAISBORD, 2009, p. 1).

A partir disso, buscamos suscitar algumas reflexões sobre como as redes sociais têm pautado o jornalismo quando o personagem é uma pessoa em situação de rua. Invisíveis ou marginalizados por grande parte da mídia, tais cidadãos encontram, muitas vezes, o olhar atento de usuários de redes sociais que estabelecem uma ponte entre este público e a narrativa jornalística.

\section{O jornalismo e as pessoas em situação de rua}




\section{míDiA \\ e

Não é de hoje que a relação entre jornalismo e minorias - tais como índios, moradores de subúrbios, migrantes e pessoas em situação de rua - é controversa. Em geral, quando encontramos notícias sobre grupos minoritários, de certa forma, em desvantagem econômica e social, o que vemos é o fortalecimento da "inferioridade" desses estratos populacionais. Neste sentido, Champagne (1997, p. 67) considera que, “quando são populações marginais ou desfavorecidas que atraem a atenção jornalística, os efeitos da mediatização estão longe de ser os que esses grupos sociais poderiam esperar".

Patrick Champagne (1997, p.70) adverte que a investigação jornalística deve ser como a investigação judiciária: "a objetividade consiste como um processo, em dar a palavra a todas as partes envolvidas, os jornalistas buscando explicitamente, em cada caso, representantes da defesa e da acusação, o 'pró' e o 'contra', a versão oficial de um incidente e a das testemunhas".

Também é comum nos depararmos com notícias que só ganharam tratamento jornalístico devido ao alto grau de violência, a exemplo de uma nota de abril de 2013, divulgada no Portal de notícias da Globo.com e intitulada "Corpo de morador de rua é achado pegando fogo em Jacupiranga, SP". Tratava-se de um homem que, após uma briga com um colega da rua, foi assassinado de maneira brutal. Outro caso que, embora não envolva a agressão física, de certo modo, reforça a exclusão de pessoas sem-teto dos Estados Unidos em um dualismo de beleza e "feiura". Quando a marca de roupas Abercrombie \& Fitch parou de produzir peças de tamanho G e GG para focalizar apenas em consumidores 'descolados, bonitos e magros', deu-se início ao protesto \#FitchTheHomeless. Greg Karber, idealizador da campanha, teve a ideia fazer um vídeo distribuindo peças de roupas para desabrigados, convocando outras pessoas para ajudar: "Juntos, podemos fazer da Abercrombie \& Fitch a marca número um entre moradores

\footnotetext{
${ }^{5}$ Disponível em:<http://g1.globo.com/sp/santos-regiao/noticia/2013/04/morador-de-rua-e-queimadovivo-apos-briga-em-jacupiranga-sp.html>. Acesso em: 27 jun. 2013.
} 
de rua" 6, explicou. O caso ganhou grande repercussão nas redes sociais e, posteriormente, com o prejuízo que todo esse movimento trouxe para a confecção, Mike Jeffries, porta-voz da empresa, declarou-se arrependido por suas afirmações e disse ainda a $A \& F$ se preocupa com a diversidade e com a inclusão ${ }^{7}$.

Sobre divulgações jornalísticas desse tipo, Theresa Christina Frazão (2010) faz uma importante reflexão:

\begin{abstract}
É desejável, até mesmo obrigatório, que valores éticos e princípios deônticos sobreponham-se à ânsia do fazer relatos simplificados e eivados de lugar comum. Também é necessário furtarem-se a emitir juízo de valor, sem medir as consequências, e opinar com atitudes e princípios desumanizados, amparados em rótulos e critérios pretensamente objetivos e neutros (FRAZÃO, 2010, p.237).
\end{abstract}

Porém, longe de cometer injustiça e generalizações, alguns profissionais da imprensa não tratam dessas pessoas com a costumeira postura higienista $\mathrm{e}$ estigmatizante. A jornalista e escritora Eliane Brum, por exemplo, enxerga na população de rua a inspiração para muitas de suas reportagens. Geppe Coppini, “o único mendigo de Anta Gorda” (BRUM, 2006, p.42), município do Rio Grande do Sul, protagonizou uma crônica-reportagem do livro "A vida que ninguém vê". Nesta obra, de forma bem humorada, a jornalista coloca em dúvida se o italiano, nascido em 1908, era realmente um mendigo, já que ele nunca precisou pedir esmolas a ninguém. Outro personagem, surgido a partir de uma cena vista na cidade de São Paulo, ilustrou a reportagem "O mundo invisível de cada um", que foi publicada em 2011, na revista Época. Em janeiro de 2013, na mesma revista, Eliane Brum contou a história de Rosângela: uma moradora de rua que não tinha onde guardar o livro que estava escrevendo, por isso, enterrou-o. Em uma viagem de avião, Rosângela ficou com medo de morrer sem que ninguém

\footnotetext{
${ }^{6}$ Disponível em:<http://exame.abril.com.br/marketing/noticias/campanha-da-web-da-roupas-daabercrombie-a-moradores-de-rua $>$. Acesso em: 27 jun. 2013.

${ }^{7}$ Disponível em:<http://siterg.terra.com.br/rgtv/2013/05/16/abercrombie-fitchthehomeless/>. Acesso em: 27 jun. 2013.

${ }^{8}$ Disponível em:<http://revistaepoca.globo.com/Sociedade/noticia/2011/11/o-mundo-invisivel-de-cadaum.html>. Acesso em: 24 out. 2013.
} 


\section{míDiA e DiAno}

soubesse onde a obra estava escondida e resolveu confidenciar o esconderijo para a jornalista, caso acontecesse um acidente ${ }^{9}$.

Outro profissional que demonstra postura cuidadosa com pessoas em situação de rua é Alberto Gaspar, da Rede Globo de Televisão. Na edição do dia 10 de maio de 2013 do Globo Repórter, voltada a desabrigados, o jornalista contou a história de "Toninha", uma senhora com "anomalias psíquicas" que vaga pelas ruas da cidade de São Paulo há quatro décadas ${ }^{10}$. A mulher foi tratada de forma respeitosa durante toda a narrativa, apesar de ter se comportado agressivamente diante das câmeras e não ter estabelecido um diálogo consciente com o jornalista. Gaspar, deixando-se 'escapar' propositalmente da imparcialidade jornalística, deu um tom afetuoso à reportagem quando contou que conhecia a personagem lendária há bastante tempo e, sempre que a via, pagava-lhe um café: "Calma, Toninha, calma. Sou amigo seu. Te conheço. Tudo bem com você? (...) Tá tudo bem? Prazer em te ver, Toninha”, o jornalista acena com a mão e encerra a narrativa.

\section{Reaproximados pela tecnologia}

Nos últimos anos, as ferramentas de comunicação e tecnologia, através das redes sociais, têm aproximado amigos e familiares que vivem distantes. Segundo dados do World Map of Social Networks houve um crescimento acentuado no uso do Facebook, rede que atingiu a marca de 1,189 bilhão de usuários ativos em dezembro de $2013^{11}$. Estes usuários dividem informações, valores e crenças com seus conhecidos próximos e com aqueles que, embora distantes geograficamente, compartilham dos mesmos interesses.

\footnotetext{
${ }^{9}$ Disponível em:<http://revistaepoca.globo.com/Sociedade/eliane-brum/noticia/2013/01/rosangela-e-olivro-enterrado.html $>$. Acesso em: 24 out. 2013.

${ }^{10}$ Disponível em:< http://g1.globo.com/globo-reporter/noticia/2013/05/conheca-o-homem-que-largoutudo-para-fugir-das-drogas-e-mulher-que-ha-40-anos-vaga-pelas-ruas-de-sp.html >. Acesso em: 8 jul. 2013.

${ }^{11}$ Disponível em:< http://vincos.it/world-map-of-social-networks/>. Acesso em: 27 fev. 2014.
} 


\section{míDiA

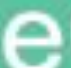

Entretanto, apenas aqueles que possuem o equipamento necessário (celular, computador, notebook) e a conexão com Internet têm acessos a essas "facilidades" da atualidade, o que acaba excluindo quem não têm condições de pagar por estes serviços.

Pensando em incluir digitalmente a população em situação de rua, três estagiários (Rosemary Melchior, Robert Weeks e Willy Wang) de uma agência de publicidade de Nova Iorque criaram, em 2011, a iniciativa Underheard (@ underheardinNY) com o objetivo de permitir com que quatro sem-teto (Daniel, Derrick, Albert e Carlos) pudessem expressar seus pensamentos, sentimentos e ações através do Twitter. Eles forneceram um telefone móvel pré-pago, criaram uma conta na rede social, ensinaram os desabrigados a usar o microblog e liberaram um mês de mensagens de texto ilimitadas. Segundo os idealizadores, a missão do projeto era utilizar a mídia social para criar uma interação real e tornar os homelesness ${ }^{12}$ parte de nossa comunidade global $^{13}$, já que eles, com frequência, sofrem preconceitos e humilhações.

De acordo com informações do site Mashable ${ }^{14}$, entre janeiro de 2009 e janeiro de 2010, o número total de pessoas desabrigadas em Nova Iorque subiu cerca de $30 \%$, sem contar com as dezenas de milhares de usuários que pernoitam em abrigos. Um desses usuários é Daniel Morales (Danny), participante do Underheard. Porto-riquenho, ele se mudou para os Estados Unidos em $1969^{15}$. Trabalhava como segurança quando sofreu um acidente e, lesionado, ficou impossibilitado de executar tarefas. Enquanto esperava pelos benefícios de segurança social, aos 58 anos, passou a sobreviver sem renda e a depender da ajuda da instituição NYC Rescue Mission.

O que Danny não sabia é que o projeto-piloto desenvolvido pelos estagiários da agência de publicidade mudaria sua vida. Após postar no Twitter uma mensagem dizendo que estava à procura de sua filha Sarah Rivera, que não via há uma década, o tweet e espalhou pelos seus três mil seguidores e, no dia seguinte, sua filha lhe

\footnotetext{
${ }^{12}$ Termo utilizado internacionalmente para designar pessoas em situação de rua.

${ }^{13}$ Disponível em:<http://underheardinnewyork.com/about>. Acesso em: 1 jul. 2013.

${ }_{14}$ Disponível em:<http://mashable.com/2011/02/16/homeless-tweets-underheard/>. Acesso em: 1 jul. 2013.

${ }^{15}$ Disponível em:<http://underheardinnewyork.com/bios>. Acesso em: 1 jul. 2013.
} 


\section{míDiA \\ e DiAno}

telefonou. Eles se encontraram em Nova Iorque e, neste encontro, ele pode conhecer seus dois netos, Navaeh Cuff e Akai Carranza ${ }^{16}$.

O caso, divulgado nos principais veículos de comunicação do mundo, foi parar no livro "A cultura da participação", de Clay Shirky, professor do Programa de Telecomunicações Interativas da Universidade de Nova Iorque. Ao analisar as mídias sociais, Shirky (2011) explica que as pessoas colaboram umas com as outras em busca de seus valores, interesses e crenças para atingirem suas metas, seus projetos e seus sonhos.

No Brasil, mais recentemente, houve um caso parecido de reencontro familiar, o de Raimundo Arruda Sobrinho, 75 anos, vinte deles vivendo no canteiro central da Avenida Pedroso de Morais, na cidade de São Paulo. Nascido na zona rural de Goiás, Raimundo foi para a capital paulista na década de 1960 para estudar o Ensino Médio. No começo, morava na casa de amigos, depois trabalhou como vendedor de livros e jardineiro, mas o que recebia não era suficiente para pagar o aluguel de um quarto e ele acabou indo para as ruas. Nessa mesma época, cessou a comunicação com sua família ${ }^{17}$.

Também chamado de "poeta da vida", ele foi um dos personagens do documentário “À margem da imagem”, dirigido por Evaldo Mocarzel (2003). No filme, ele aparece em vários trechos, de barbas e cabelos compridos, falando coisas desconexas. Conforme Mattos (2006), nestes casos, são parcas as chances de ressocialização ou restabelecimento de vínculos, pois essas pessoas estão presas à loucura e à rua, vivendo em um mundo criado na imaginação. Entretanto, a vida de Raimundo mudou quando Shalla Monteiro cruzou seu caminho e criou um perfil no Facebook (Figura 1), em agosto de 2011, para divulgar suas poesias ${ }^{18}$. A publicitária era

\footnotetext{
${ }^{16}$ Disponível em:<http://www.bbc.co.uk/news/world-us-canada-12586433>. Acesso em: 1 jul. 2013.

${ }^{17}$ Disponível em:<http://g1.globo.com/sao-paulo/noticia/2012/05/morador-de-rua-de-sp-reencontrafamilia-apos-perfil-criado-no-facebook.html>. Acesso em: 1 jul. 2013.

${ }^{18}$ Disponível em:<https://www.facebook.com/ocondicionado>. Acesso em: 1 jul. 2013.
} 


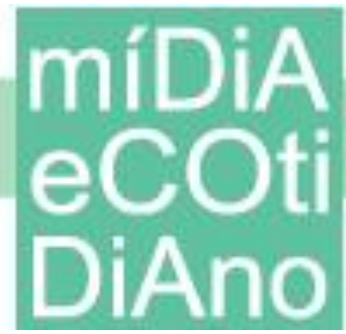

\section{PPGMC}

uma das simpatizantes do poeta e sempre ganhava minipáginas com escritos do amigo, que, até hoje, assina os textos com o pseudônimo de "O Condicionado" 19 .

Menos de um mês depois, Francisco, um dos irmãos de Raimundo, que vive em Goiânia (GO), encontrou o perfil na Internet e, imediatamente, entrou em contato com Shalla, que passou todas as informações para o reencontro dos dois. Após alguns dias, Francisco foi até o canteiro central da Avenida Pedroso de Morais para "resgatar" o irmão poeta.

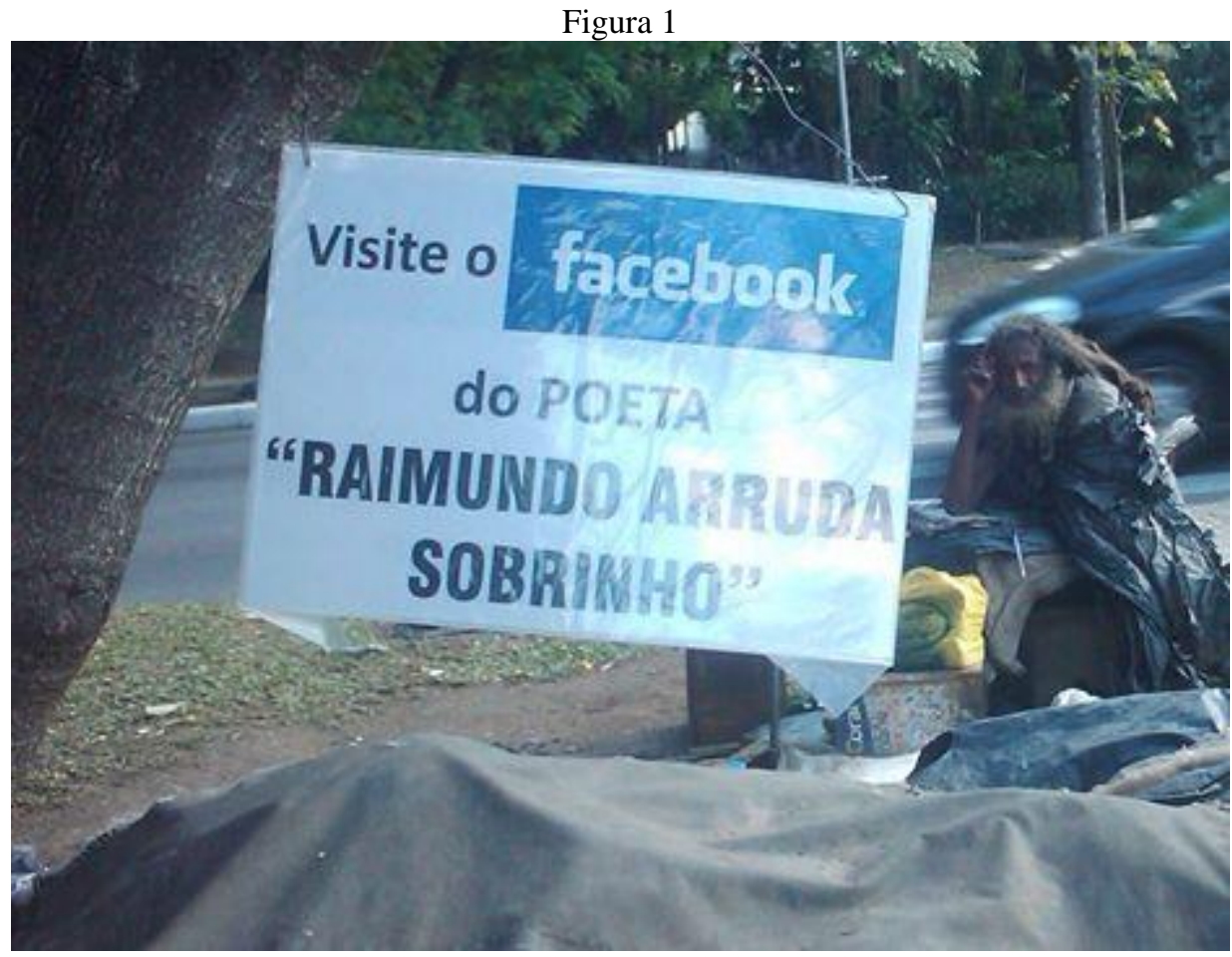

Fonte: Facebook/17 de out. 2011

Um ano depois, o site da Folha publicou que Raimundo já estava vivendo com sua família e tentando se readaptar. Nesta reportagem, que tratou de sua trajetória de vida, ele declarou:

\footnotetext{
${ }^{19}$ Disponível em:<http://noticias.terra.com.br/brasil/cidades/sp-poeta-da-rua-reencontra-familia-e-passapor-tratamento,b14e4cb8511da310VgnCLD200000bbcceb0aRCRD.html>. Acesso em: 1 jul. 2013.
} 


\section{PPGMC}

fundamental é o diário. As minipáginas faço o que posso. Aqui não tem muita necessidade delas. Lá precisava para dar a quem me desse alguma coisa, tenho a necessidade moral de retribuir com qualquer coisinha (informação verbal) ${ }^{20}$.

Shalla mantém contato periodicamente com Raimundo e continua atualizando o perfil dele no Facebook. Ela posta fotos do escritor com a família e das minipáginas, como esta, intitulada "Sonho": "Uma humanidade/ cujos membros funcionem/ com a perfeição de todas as peças/ do mais refinado engenho”. A publicitária organizou um livro com os poemas de Raimundo que está na iminência de ser lançado. No aniversário de dez anos da rede social, a página de Histórias do Facebook Brasil selecionou dez histórias de conexões criadas através da plataforma. Raimundo e Shalla protagonizaram uma delas, intitulada: "O condicionado"21. A amizade de Shalla e Raimundo (Figura 2) também foi conhecida por meio do Youtube, onde foi contada de forma lúdica no vídeo “Dois, Shalla e Raimundo: saindo das ruas", dirigido por Rafinha Bastos e Léo Rapini²2.

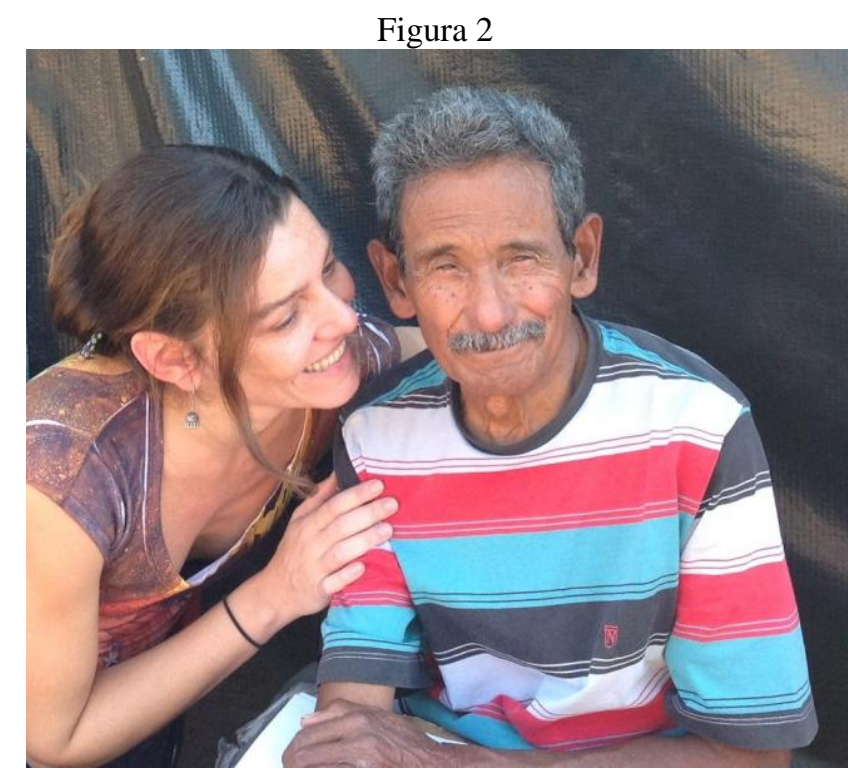

\footnotetext{
${ }^{20}$ Disponível em:< http://www1.folha.uol.com.br/cotidiano/2013/05/1278751-morador-de-rua-escritorconta-nova-historia-apos-ser-levado-para-casa.shtml>. Acesso em: 1 jul. 2013.

${ }^{21}$ Disponível em: $<$ http://facebookstories.com/10 $>$. Acesso em: 27 fev. 2014.

${ }^{22}$ Disponível em: $<$ http://www.youtube.com/watch? $\mathrm{v}=\mathrm{VffcwEtmHHU}>$. Acesso em: 16 dez. 2013.
} 


\section{PPGMC}

Em março de 2014, Raimundo e sua família estiveram presentes no programa Encontro com Fátima Bernardes, da Rede Globo. Shalla fez uma participação online e contou que, na época em que vivia na rua, Raimundo não pedia nada a ninguém. Mesmo assim, no site do programa, a chamada do assunto foi: "Ex-mendigo poeta emociona famosos e recebe propostas para editar livro". O destaque é dado ao termo exmendigo. Se o poeta não mendigava, ele não pode ser considerado um ex-mendigo. Além disso, mesmo sendo o protagonista da história, Raimundo pouco falou. Em determinado momento, a apresentadora quis saber por qual motivo ele assinava seus escritos como "O condicionado". Em vez de questioná-lo diretamente, Fátima Bernardes optou por perguntar isso à Shalla ${ }^{23}$. O episódio pode ser explicado por meio da tese de Frazão (2010) sobre a invisibilidade do sujeito no discurso jornalístico. Mesmo com acesso aos moradores de rua, muitos jornalistas optam por ouvir outras pessoas julgadas mais capazes de falar por eles. No caso de Raimundo, mesmo não vivenciando mais a situação de vulnerabilidade, pode-se perceber um ranço do ofuscamento da fonte.

No Brasil, nos Estados Unidos e no mundo todo existem milhares de pessoas como Daniel Morales e Raimundo Arruda Sobrinho, que, por algum desencontro, ou por terem traçados rotas que os levaram a caminhos diversos, ficaram em situação de rua. Alguns vivem desta forma por preferência. Já outros demandam ajuda para resgatar vínculos afetivos e de pertencimento que foram se perdendo nos "caminhos" percorridos. Para estes que desejam resgatar partes da vida deixadas para trás, as redes sociais vêm funcionando como uma poderosa ferramenta de conexão, reintegração e resgate.

\footnotetext{
${ }^{23}$ Disponível em:http://gshow.globo.com/programas/encontro-com-fatima-bernardes/OPrograma/noticia/2014/03/ex-mendigo-poeta-vai-ao-encontro-nao-leio-jornal-nem-vejo-tv-desde1976.html. Acesso em: 1 abr. 2014.
} 


\section{míDiA \\ e \\ DiAno}

\section{Considerações finais}

As redes sociais podem ser consideradas, de um lado, um mecanismo de controle social muito utilizado por diversas instituições e, por outro, um espaço democrático dos usuários para, além de outras coisas, expressar opiniões e divulgar assuntos de interesse. Desde seu surgimento, os meios de comunicação se beneficiam destes dois polos. As histórias de Raimundo Sobrinho e de Daniel Morales, por exemplo, só foram contadas pelo jornalismo em decorrência das redes sociais.

Desta forma, a tecnologia quando utilizada de forma colaborativa, humanizada e horizontalizada, vem contribuindo para desvendar o olhar dos jornalistas diante da realidade que precisa ser reportada. Ademais, tais plataformas digitais têm possibilitado o restabelecimento de vínculos familiares que culminam com a melhora da qualidade de vida dos envolvidos.

Como mediador de saberes e relatos da memória coletiva, o jornalismo deve atentar para sua função social de pôr em pauta temas que são mais que boas histórias, são indícios de uma sociedade que precisa ser refletida para que possa ser modificada por seus cidadãos. Moretzsohn (2013, texto digital) ressalta que o jornalismo, entre várias coisas, é: "O exercício do senso crítico no calor da hora. Por isso é tão difícil. Por isso é tão necessário. E por isso, também, é tão necessária a crítica ao jornalismo que descumpre seu papel".

O jornalismo precisa atentar para histórias que mostrem além das fatalidades da vida, que insinuem transcendências, que denunciem problemas sociais e apontem soluções. Alberto Gaspar e Eliane Brum são exemplos de jornalistas que comprovam esta possibilidade por meio de seus trabalhos.

\section{Referências}




\section{PPGMC}

\section{DiAno}

À MARGEM da imagem (Documentário). Direção: Evaldo Mocarzel. Produção: Malu Oliveira. Roteiro: Evaldo Mocarzel e Maria Cecilia Loschiavo dos Santos. São Paulo: SP Filmes de São Paulo, 2003. DVD (72 min).

BRUM, Eliane. A vida que ninguém vê. Porto Alegre: Arquipélago Editorial, 2006.

CHAMPAGNE, Patrick. A visão mediática. In: BOURDIEU, Pierre et al. A Miséria do mundo. Petrópolis, RJ: Vozes, 1997. p. 63-80.

FRAZÃO, Theresa Christina Jardim. O morador de rua e a invisibilidade do sujeito no discurso jornalístico. 2010. [Tese Doutorado]- Programa de Pós-Graduação em Linguística. Universidade de Brasília, Brasília, 2010.

HENN, Ronaldo Cesar (2013). Apontamentos sobre o ciberacontecimento: o caso Amanda Tood. Anais... XXII Encontro Anual da Compós, Universidade Federal da Bahia, Salvador, 4-7 de jun. 2013. Disponível em: < http://encontro2013.compos.org.br/anais/estudos-de-jornalismo/>. Acesso em: 17 set. 2013.

JUNGBLUT, Airton Luiz. Acontecimentos em rede: reflexões etnográficas sobre ciberacontecimentos. In: V Simpósio Nacional ABCiber - 16-18 de Nov. 2011. Florianópolis, UDESC/UFSC.

MATTOS, Ricardo Mendes. Situação de rua e modernidade: a saída das ruas como processo de criação de novas formas de vida na atualidade. 2006. 244f. Dissertação (Mestrado em Psicologia)- Programa de Pós-Graduação em Psicologia, Universidade São Marcos, São Paulo, 2006.

MORETZSOHN, Sylvia Debossan. Redes sociais, boatos e jornalismo. In: Observatório da imprensa. Disponível em: $<$ http://www.observatoriodaimprensa.com.br/news/view/_ed751_redes_sociais_boatos_ e_jornalismo>. Acesso em: 8 jul. 2013.

MORIN, Edgar. Introdução ao pensamento complexo. Tradução Eliane Lisboa. Porto Alegre: Sulina, 2006.

MOTTA, Luiz Gonzaga. Por que estudar narrativas?. In: LADEIRA MOTA, Célia; MOTTA, Luiz Gonzaga e CUNHA, Maria Jandyra (orgs). Narrativas midiáticas. Florianópolis: Insular, 2012.

RINCÓN, Omar. Narrativas mediáticas. Barcelona: Gedisa, 2006. 
RUBLESCK, Anelise. Agendamento e mediação jornalística no jornalismo líquido. In: Comunicologia - Revista de Comunicação e Epistemologia da Universidade Católica de Brasília. $\quad \mathrm{N}^{\circ} \quad 4, \quad 2011 . \quad$ Disponível $\quad$ em: http://portalrevistas.ucb.br/index.php/RCEUCB/article/view/2882/1780>. Acesso em: 8 jul. 2013.

SOUSA, Jorge Pedro. Teorias da notícia e do Jornalismo. Chapecó/Florianópolis: Argos/Letras Contemporâneas, 2002, pp. 11-113.

SHIRKY, Clay. A cultura da participação: criatividade e generosidade num mundo conectado. Rio de Janeiro: Zahar, 2011.

YIN, Robert K. Estudo de Caso: Planejamento e Métodos. Tradução Daniel Grassi. $2^{\text {a }}$ edição. Porto Alegre: Bookman, 2001.

WAISBORD, Silvio. A sociedade civil pode mudar o jornalismo?. In: Dossiê da Sociedade Brasileira de Pesquisa em Jornalismo, SBPJor, 2009. Disponível em: <http://bjr.sbpjor.org.br/bjr/article/view/192>. Acesso: 29. mai. 2013.

ZAGO, Gabriela. Recirculação jornalística no twitter: filtro e comentário de notícias por interagentes como uma forma de potencialização da circulação. Dissertação de mestrado. Porto Alegre: PPGCOM UFRGS, 2011. Disponível em: <http://www.lume.ufrgs.br/handle/10183/28921>. 